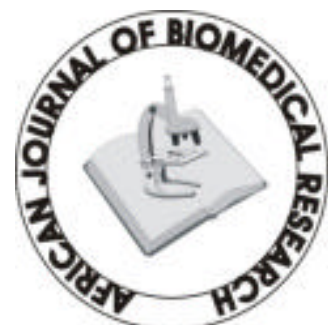

Full-text available at http://www.ajbrui.com http://www.bioline.br/md http://www.ajol.com

Received:

May 2006

Accepted (Revised) :

February 2007

Published

September 2007
Full Length Research Article

\section{Isotonic Quadriceps-Hamstring Strength Ratios of Patients with Knee Osteoarthritis and Apparently Healthy Controls}

\author{
Adegoke B.O.A. *, Mordi E.L., Akinpelu O.A., Jaiyesimi A.O. \\ Department of Physiotherapy, College of Medicine, \\ University of Ibadan, Nigeria
}

\begin{abstract}
This study was conducted to compare the isotonic quadriceps-hamstring $(Q / H)$ ratios of patients with knee osteoarthritis $(O A)$ and apparently healthy control subjects. The relationships between $Q / H$ ratio and each of height, total body weight, age and Quetelet index of both groups were also investigated. Participants in the study were twenty patients with knee OA (13 females and 7 males) and 20 (11 females and 9 males) apparently healthy control subjects. The mean ages of the $O A$ and control subjects were $53.20 \pm 8.51$ and $40.05 \pm 7.94$ years respectively. Isotonic hamstring strength (ITHS) and isotonic quadriceps strength (ITQS) were estimated using the one repetition maximum (1-RM) format. $Q / H$ ratio was estimated by dividing the quadriceps muscle strength by the hamstring muscle strength. Data were summarized as mean and standard deviation. The independent t-test was used to compare the mean of the variables of age, weight, height, Quetelet index (QI), isotonic quadriceps strength (ITQS), isotonic hamstrings strength $(I T H S)$ and isotonic quadriceps/hamstrings strength ratio $(Q / H)$ between the two groups. The $\propto$-level was set at 0.05. Results showed a significantly higher ITQS $(p=0.01)$ and ITHS $(p=0.00)$ for the apparently healthy control subjects than the patients with knee OA. The patient group had a significantly higher age $(p=0.00)$, weight $(p=0.03)$ and $Q I(p=0.01)$ than the control group but the two groups of subjects had similar Height $(p=0.30)$ and $Q / H$ ratio $(p=0.07)$.
\end{abstract}

(Afr. J. Biomed. Res. 10: $211-216)$

\section{Key Words:}

Osteoarthritis, quadriceps-hamstring ratio, muscular strength, isotonic strength

*Address for Correspondence: badegoke@comui.edu.ng

Abstracted by:

African Index Medicus (WHO), CAB Abstracts, Index Copernicus, Global Health Abstracts, Asian Science Index, Index

Veterinarius, Bioline International , African Journals online 


\section{INTRODUCTION}

Strength is defined as the ability of a muscle or group of muscles to develop tension and a resulting force during a maximum effort either dynamically or statically, in relation to the demands placed upon it (Kisner and Colby,1996) Muscle strength, like many other human capabilities is a complex phenomenon to characterize because of its wide range of normal variability and its being affected by many factors including age, gender, cross-sectional area of the muscle, types of muscle fibre and type of contraction (Smith et al, 1998). Symptomatic knee OA occurs in approximately $10 \%$ of individuals over 65 years of age and may affect up to $2 \%$ of the adult population (Felson et al, 1992). The principal changes in knee OA are joint space narrowing due to degeneration and disappearance of articular cartilage, sharpening of articular margins and intra-articular structures (e.g. tibial tubercules), bony sclerosis or eburnation, osteophytes and marginal lipping and bony cysts (Brandt, 2001).

Muscle plays a major role in the structure and function of joints as evident by disuse atrophy of the quadriceps femoris muscle that accompanies knee joint pain (Swash, 1995). Weakness of the quadriceps muscle has equally been noted by the American Academy of Orthopaedic Surgeons (2002) as a risk factor for structural damage to the knee joint. .

Minor et al (1989, as cited by Kovar et al, 1992) had observed that patients with OA and rheumatoid arthritis are significantly deconditioned when compared with apparently healthy age- and sex-matched control subjects. Cheing and Hui-Chan (2000) also found the isometric peak torque of both the quadriceps and hamstrings of the affected leg of patients with knee OA to be lower than those of the agematched controls.

The strength relationship between the quadriceps femoris and hamstring muscles have been measured and reported by various researchers (Noose, 1982; Holmes and Alderink, 1984; Gross et al, 1990; Hayes and Falconer, 1992; Cheing and Hui-Chan, 2000). Gross et al (1990) reported the isokinetic $\mathrm{Q} / \mathrm{H}$ ratio for apparently healthy subjects to be $1.70: 1$ and $1.37: 1$ at $60 \% \mathrm{sec}$ and $180^{\circ} / \mathrm{sec}$ angular velocities of limb movement respectively.

Hayes and Falconer (1992) investigated the effect of $\mathrm{OA}$ on the isometric $\mathrm{Q} / \mathrm{H}$ and observed that both quadriceps and hamstrings were weak, with relatively greater weakness in the quadriceps femoris muscle. The mean isometric $\mathrm{Q} / \mathrm{H}$ ratio was hence found to be 1.43 , a value below ratios reported for young healthy adults whose isometric $\mathrm{Q} / \mathrm{H}$ ratio was 2:1 (Hayes and Falconer, 1992). There is presently a dearth of literature on the effect of osteoarthritis on the quadriceps and hamstring muscles among Nigerians with OA of the knee. The purpose of this study therefore was to compare the isotonic $\mathrm{Q} / \mathrm{H}$ ratio of patients with $\mathrm{OA}$ and their age- and sex-matched apparently healthy controls.

\section{MATERIALS AND METHODS}

\section{Subjects:}

Subjects for the study were 20 patients ( 7 maks and 13 females) with clinically diagnosed OA of the knee joint and 20 (9 males and 11 females) apparently healthy control subjects recruited using the purposive sampling technique.

\section{Instruments:}

Data were collected using the following instruments:

1. A bathroom weighing scale ("Hanson" Ireland): was used to measure the subjects' total body weight in $\mathrm{kg}$, to the nearest whole number.

2. Height meter: was used to measure the height of subjects to the nearest centimeter.

3. A specially designed high testing table with a backrest tilting at an angle of $120^{\circ}$ to the horizontal. The table was high enough to allow the subject's feet to dangle freely while the subject was in a sitting position for the quadriceps strength testing procedure.

4. Two non-elastic straps: were used to ensure stabilization of the trunk and thighs of each 
subject, thereby preventing any unwanted movement of the parts.

5. Metal weights ( $2 \mathrm{~kg}$ to $6 \mathrm{~kg}$ ) for determining each subject's repetition maximum.

6. Delorme Boot: this is an iron contraption to which the metal weights were attached during strength testing procedures.

\section{Procedure:}

The rationale behind the study was explained to the subjects and their informed consent was sought and obtained. Subjects' age as at last birthday was then sought and recorded. In the subjects with clinically diagnosed OA of the knee, the strength of the arthritic limb was determined while the strength of the dominant limb was tested in the control group.

\section{Hamstring Muscle Strength Testing:}

The isotonic hamstring strength of all subjects was determined with the subject in a prone lying position with his/her feet hanging over the edge of the plinth. A pillow was placed under the knees, to prevent compression of the patella between the femur and the plinth. The trunk and thighs were also strapped to the plinth to prevent extraneous movements of other parts of the body during hamstring strength testing. A Delorme boot was strapped to the foot of the affected limb of the patient with knee OA. A load of comfortable weight, with respect to each subject was then randomly selected by us and strapped around the ankle of the subject who was then instructed to flex his knee against the resistance offered by the load. Each subject lifted the weights within their limits of pain and muscle fatigue as suggested by Puett and Griffin (1994). The number of times the subject lifted the load through full range of motion (from knee extension to knee flexion) before getting fatigued was recorded as the load's equivalent repetition maximum (RM.).

\section{Quadriceps - Femoris Strength Testing}

The determination of isotonic quadriceps strength of all subjects was done with the patient in a high sitting position on a specially designed seat that had its backrest tilting at an angle of $120^{\circ}$ to the horizontal. This position placed a stretch on the rectus femoris aspect of the quadriceps femoris muscle, thereby causing the force of the extensors of the knee to be increased (Smith et al, 1998). The patient's back was strapped to the backrest of the testing table while the upper third of the thigh was strapped to the sitting platform, so as to prevent extraneous movements of the thigh during tests. A Delorme boot was strapped to the foot of the leg to be tested and metal weights were attached to the boot. The patient was instructed to lift the load by extending the knee of the limb to which the load was attached. The number of times he performed the lift from $90^{\circ}$ of knee flexion to full knee extension before fatigue set in was recorded as the weight's equivalent repetition maximum.

\section{Computations:}

The following computations were made with the data collected:

1. Quetelet Index $=$ Weight $(\mathrm{kg}) / \mathrm{Height}^{2}\left(\mathrm{~m}^{2}\right)$ (Swash, 1995).

2. Isotonic hamstring strength and isotonic quadriceps femoris strength: The IRM for the hamstrings and quadriceps femoris of each subject was estimated using the formula:

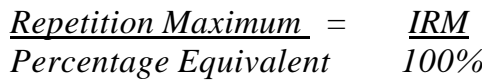
.... (Belanger et al, 1984)

The calculated IRM values were taken as the subject's isotonic hamstring and quadriceps strengths, measured in kilogram, to the nearest decimal place.

3. The isotonic quadriceps/hamstring strength ratio was calculated thus:

\section{$Q /$ H ratio $=\underline{\text { Isotonic quadriceps strength value }}$ Isotonic hamstring strength value}

\section{Data Analysis}

(Aagaard et al, 1998)

(i) Mean and SD were computed for all the variables (age, weight, height, QI, ITQS, ITHS and $\mathrm{Q} / \mathrm{H})$.

(ii) Independent ttest was used to compare the mean of all the variables (age, weight, height, QI, ITQS, ITHS and $\mathrm{Q} / \mathrm{H}$ ) between the two groups 


\section{RESULTS}

The physical characteristics of all subjects are presented in Table 1. Independent t-test revealed that the OA patients were significantly older $(\mathrm{p}=0.00)$, weighed significantly more $(\mathrm{p}=$ 0.03 ) and had significantly higher Quetelet index $(\mathrm{p}=0.01)$ than the control subjects. No significant difference $(\mathrm{p}=0.30)$ was however found between the mean heights of subjects in the two groups. The table also shows the muscle strengths and strength ratio for the two groups of subjects. The independent t-test showed that the control subjects had significantly higher ITQS $(p=0.01)$ and ITHS $(\mathrm{p}=0.00)$ than the subjects with knee OA. There was however no significant difference $(p=0.07)$ between the $\mathrm{Q} / \mathrm{H}$ ratios of the two groups.

Table 1

Physical Characteristics of the Subjects

\begin{tabular}{|c|c|c|c|c|}
\hline Variables & $\begin{array}{l}\text { OA Subjects } \\
\text { Mean } \pm \text { S.D }\end{array}$ & $\begin{array}{l}\text { Controls Subjects } \\
\text { Mean }+ \text { S.D }\end{array}$ & $\begin{array}{l}\text { Calculated } \\
\text { t-value }\end{array}$ & P-value \\
\hline Age (years) & $53.20 \pm 8.51$ & $40.05 \pm 7.94$ & 5.05 & $\mathbf{0 . 0 0 *}$ \\
\hline Weight (kg) & $76.05 \pm 22.13$ & $63.40 \pm 10.80$ & 2.30 & 0.03* \\
\hline Height (m.) & $1.63 \pm 0.07$ & $1.65 \pm 0.70$ & 1.04 & $\mathbf{0 . 3 0}$ \\
\hline Quetelet Index $\left(\mathrm{kg} / \mathrm{m}^{2}\right)$ & $28.48 \pm 7.47$ & $22.24 \pm 3.61$ & 2.83 & 0.01* \\
\hline
\end{tabular}

* Indicates significant difference at $\mathbf{a}=.05$

Table 2

T-Test Comparing Strength and Quadriceps - Hamstring Strength Ratios of Subjects With OA Knee and Control Subjects

\begin{tabular}{lllll}
\hline Variables & $\begin{array}{c}\text { OA Subjects } \\
\text { Mean } \pm \text { S.D }\end{array}$ & $\begin{array}{l}\text { Control Subjects } \\
\text { Mean } \pm \text { S.D }\end{array}$ & $\begin{array}{l}\text { Calculated } \\
\text { t-value }\end{array}$ & P-value \\
\hline ITQS (kg.) & $\mathbf{8 . 5 9} \pm \mathbf{2 . 8 0}$ & $\mathbf{1 0 . 7 4} \pm 2.33$ & $\mathbf{2 . 6 5}$ & $\mathbf{0 . 0 1 *}$ \\
ITHS (kg.) & $\mathbf{6 . 6 9} \pm 3.26$ & $\mathbf{1 0 . 4 5} \pm 3.25$ & $\mathbf{3 . 6 5}$ & $\mathbf{0 . 0 0 *}$ \\
Q/H Ratio & $1.64 \pm 1.01$ & $1.17 \pm 0.52$ & $\mathbf{1 . 8 6}$ & 0.07 \\
\hline
\end{tabular}

* Indicates significant difference at $\mathbf{a}=\mathbf{. 0 5}$

\section{DISCUSSION}

In the two groups tested in this study, the ITHS was found to be less than the ITQS, implying greater strength in knee extensor muscles as compared with knee flexor muscles. This is in consonance with reports by Smith et al (1998) that peak torque for quadriceps fermoris muscle is greater than that of the hamstrings.

This present study recorded a significant difference in both ITQS and ITHS of the OA knee and control subjects, with the strength of the control group being significantly greater than that of the group of patients with knee OA. This finding supports the findings of Slemenda et al (1997) and Cheing and HuirChan (2000), who however went further to observe that $\mathrm{OA}$ of the knee weakened both the quadriceps and hamstring muscle groups. This last statement cannot be reasonably upheld by this present study due to the paucity of age- matched control subjects without OA knee

The ratio of quadriceps to hamstring muscle strength is important for the stability of the knee and for from excessive stress (Hayes and Falconer, 1992). Wathen (1994) suggested an isotonic Q/H ratio of 3:2 for apparently healthy individuals. Tan et al, (1995) as cited by Nicholas (1999) reported no difference in both the isokinetic and isometric hamstring to quadriceps strength ratios of $\mathrm{OA}$ patients and pain-free age- and sex-matched controls. Brandt et al (1999) however reported that isokinetic $\mathrm{Q} / \mathrm{H}$ ratio was unaffected by $\mathrm{OA}$ progression. The differences between the findings 
of the various studies can be explained by the submission of Kannus (1988) that results of studies on the strength of knee musculature vary among others because of differences in testing procedures in terms of the instructions given to the subjects, positions used during testing (supine, prone, seated, hip position), degree of subjects' stabilization or lack of it, one limb or both limbs tested, recording of one highest value or the mean of multiple trials, criterion for determining strength (1RM or $10 \mathrm{RM})$ and so on.

This study showed that the presence of OA did not lead to a statistically significant difference between the isotonic $\mathrm{Q} / \mathrm{H}$ ratio of subjects with and without knee $\mathrm{OA}$. Indeed, the $\mathrm{Q} / \mathrm{H}$ ratio of patients with OA in this study was higher (though not significantly) than the $\mathrm{Q} / \mathrm{H}$ ratio of the control subjects This is contrary to the finding by Hayes and Falconer (1992), of a lowered isometric Q/H ratio (1.43) in the group of patients with OA knee when compared with the young apparently healthy adults $(\mathrm{Q} / \mathrm{H}$ ratio of 2.0). The contrast in results between our study and that of Hayes and Falconer (1992) may be a reflection of the difference in the type of strength measured in both studies. Our study evaluated the isotonic strength of the participants while Hayes and Falconer evaluated isometric strength of their subjects. In our study, the $\mathrm{Q} / \mathrm{H}$ ratio of the $\mathrm{OA}$ group was found to be greater than that of the control group, implying that OA of the knee probably leads to a greater reduction in the strength of the hamstrings than quadriceps muscle group.

An apparent limitation of this study is our inability to successfully match the OA patients and apparently healthy controls with respect to the anthropometric variables (weight, height and Quetelet index) which have been found from previous studies to influence the ability exhibit strength. This was occasioned by paucity of agematched apparently healthy controls without OA symptoms.

\section{CLINICAL IMPLICATION}

The finding from this study suggests that OA knee affects the hamstring muscle more than the quadriceps muscle. There is therefore a need for physiotherapists who have hitherto concentrated almost exclusively on quadriceps strengthening in OA patients to include hamstring strengthening in their management protocol.

\section{REFERENCES}

Aagaard, P; Simonsen, E. B; Magnusson, S. P; Larsson, B; Dyhre-Poulsen, P; (1998): A new concept of isokinetic hamstring: quadriceps muscle strength ratio (abstract). Am J Sports Med. 26, 231-7.

American Academy of Orthopaedic Surgeons; (2002): www3.aaos.org/research/imca/OAknee Contents/OA_Knee_ml_5.htm 1/02/05, 10.15am.

Belanger, A. Y; Noel, G; Bilodeau, L; Bountin, A; Gingras, C; Guillemette, S; (1984): L'utilization de la table de Berger pour determiner le IRM et le 10RM des muscles estenseurs du genou. Physiother Can. 36, 13.

Brandt, K. P; (2001): An atlas of osteoarthritis. The Parthenon Publishing Group. New York. 68.

Brandt, K.D; Heilman, D.K; Slemenda, C; Katz, B.P; Mazzuca, S.A; Braunstein, E.M; Bryd, D (1999): Quadriceps strength in women with radiograhically progressive osteoarthritis of the knee and those without radiographic changes. J Rheumatol. 26, 2421-7

Cheing, G. L.Y; Hui-Chan, C. W. Y; (2000): The motor dysfunction of patients with osteoarthritis in a Chinese population (abstract). Arthritis Care Res. 45, $62-68$.

Felson, D. T; Zhang, Y; Anthony, J. M.; Naimark, A; Anderson, J. J. (1992): Weight loss reduces the risk of symptomatic knee osteoarthritis in women. The Framingham study. Ann. Intern Med.116, 535.

Gross, M. T; Credle, J. K; Hopkins, L. A; Kollin, M. T; (1990): Validity of knee flexion and extension peak torque prediction model. Phys. Ther. 70, 3- 10 .

Hayes, K. W; Falconer, J; (1992): Differential muscle strength decline in osteoarthritis of the Knee. A developing hypothesis (abstract). Arthritis Care Res. 5, $24-28$.

Holmes, J. R; Alderink, G. J; (1984): Isokinetic strength characteristics of the quadriceps-femoris and hamstring muscles in high school students. Phys. Ther. 64, $914-918$.

Kannus P (1988): Ratio of hamstring $t$ quadriceps femoris muscle strength in the anterior cruciate ligament insufficient knee. Relationship to long-term recovery. Phys .Ther. 68, 961-2.

Kisner,C; Colby, L.A (1996): Therapeutic exercisesFoundation and Techniques. $3^{\text {rd }}$ ed. India, Jaypee Brothers 14, 86. 
Kovar, P. A; Allengrante, J. P; Mackenzie, R. C; Peterson, M.G.E; Gutin, B; Charlson, M. E; (1992): Supervised fitness walking in patients with osteoarthritis of the knee. A randomized controlled trial. Ann. Intern Med. 116, 529-32.

Nicholas, J.J (1999): Exercise prescription for the arthritic patient. In: Shankar,K (1999). Exercise Presciption. Philadelphia, Hanley and Belfus Inc.284-5. Noose, L. J; (1982): Assessment of selected reports on the strength relationship of the knee musculature. J. Orthop. Sports Phys Ther. 4, 80-81.

Puett, D. W; Griffin, M. R; (1994): Published trials of non-medicinal and non-invasive therapies for hip and knee osteoarthritis. Ann. Intern Med. 121, 135.

Slemenda, C; Brandt, K.P; Heilman, D. K;
Mazzuca, S; Braunstein, E. M; Katz, B. P; Wolinsky, F. D; (1997): Quadriceps weakness and osteoarthritis of the knee (abstract). Ann. Intern Med. 127, 97-104.

Smith, L.K; Weiss, E. L; Lehmkuhl, L. P; (1998): Brunnstrom's clinical kinesiology. Jaypee Brothers Medical Publishers Ltd. New Delhi. 5th ed. 136 - 138, 146, 302 - 303, 307, 310, 317, 326.

Swash, M; (1995): Hutchison's clinical methods. W. B. Saunders Company Limited. Philadelphia. $20^{\text {th }}$ ed. 79.

Wathen, D (1994): Muscle balance. In: Baechle, T.R (1994): Essentials of strength training and conditioning. Human Kinetics, Champaign, Illinois. 